\title{
GvHD Final Lung Score 3
}

National Cancer Institute

\section{Source}

National Cancer Institute. GvHD Final Lung Score 3. NCI Thesaurus. Code C131048.

FEV1 is less than or equal to 39 percent and lung symptoms are none to severe. 